\title{
Toxicity of some new and conventional insecticides on Trichogramma chilonis Ishii and Bracon brevicornis Wesmael under laboratory condition
}

\section{Authors Info}

\section{S. Patra* and A. Samanta ${ }^{2}$}

'Division of Crop Protection, ICAR Research Complex for NEH Region, Umiam - 793 103, India

${ }^{2}$ Department of Agricultural Entomology, Bidhan Chandra Krishi Viswavidyalaya, Mohanpur, Nadia-741 252, India

*Corresponding Author Email : sandippatra47@gmail.com

Key words

Bracon brevicornis, Insecticides,

Parasitisation performance, Toxicity,

Trichogramma spp.

\section{Publication Info}

Paper received : 16.07.2016

Revised received : 28.11 .2016

Re-revised received : 20.12.2016

Accepted : 30.12 .2016

\section{Abstract}

Aim: Insecticides that are widely used to suppress various pests also disrupt the effectiveness of various natural control agents. After application of insecticides, predators and parasitoids may acquire insecticides via host, direct contact or by ingesting floral nectar and pollen. The main objective of the study was to find out the adverse effect of some new and conventional insecticides on Trichogramma chilonis Ishii and Bracon brevicornis Wesmael under laboratory condition.

Methodology: Experiments were carried out on T. chilonis and B. brevicornis in Bidhan Chandra Krishi Viswavidyalaya, West Bengal, India. The eggs of Corcyra cephalonica Stainton were used as host for laboratory rearing of $T$. chilonis, whereas full grown larvae were used for rearing of $B$. brevicornis. Three doses (half of the recommended, recommended and double the recommended dose) of pyridalyl 10EC, indoxacarb 14.5SC, chlorfenapyr 10SC, triazophos 40EC and chlorpyriphos 20EC were used along with control treatment. Persistent toxicity study was carried out only with recommended dose of each insecticide. The mortality data of different natural enemies were analyzed following CRD. The corrected percentage mortality was calculated for persistent toxicity study.

Results: Chlorpyriphos was highly toxic to $T$. chilonis with no emergence followed by triazophos (1.32$10.44 \%$ emergence) and chlorfenapyr (4.22-13.63\% emergence). Pyridalyl and indoxacarb were relatively safe towards $T$. chilonis with 70.11-77.38 and 71.51-74.94 \% adult emergence. Toxicity trend towards $B$. brevicornis was similar to $T$. chilonis. Persistent toxicity study revealed that pyridalyl and indoxacarb had short persistency, chlorfenapyr was moderately persistent while conventional insecticides (triazophos and chlorpyriphos) were highly persistent.

Interpretation: This study suggests that pyridalyl and indoxacarb can be used safely whereas chlorfenapyr, triazophos and chlorpyriphos should be used with caution in integrated pest management.

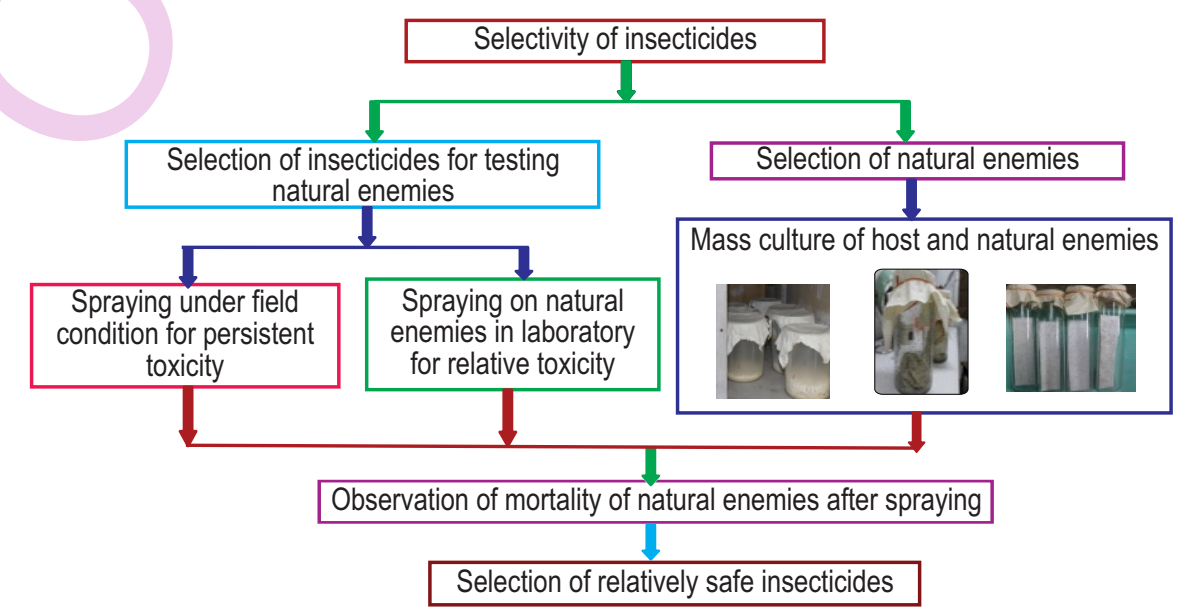




\section{Introduction}

Hymenoptera is one of the dominant orders among the entomophagous insects, both in terms of number of species and the effectiveness with which they attack the insect pests of agricultural crops. Members of the family Trichogrammatidae and Braconidae play a significant role in controlling important insect pests on different crops. Several species of Trichogramma are reared and released in millions of hectares of agricultural and forest crops in more than 30 countries around the world (Li, 1994; Zhang et al., 2010; Wang et al., 2014). Trichogramma spp. have good dispersal ability and parasitisation performance against lepidopteran pests of rice (Sharma and Aggarwal, 2015). The genus Bracon is an extremely large group with several species along with its worldwide distribution. Braconids are gregarious, idiobiont arrhenotokous ectoparasitoids that parasitize lepidopteran larvae and are important biological control agents for several stored products moth pests (Gul and Gulel 1995; Heimpel et al., 1997; Darwish et al., 2003). Bracon chinensis (Szepligeti) is widely distributed in Asia and is an important natural enemy of the larvae of various species of rice stem borer (Yasumatsu, 1967). The natural incidence of Bracon hebetor Say, Bracon greeni Ashmead and Trichogramma spp. on Earias spp. in okra fields was reported by Mani et al. (2005). Several insecticides that are widely used to suppress various pests also disrupt the effectiveness of various natural control agents. Thereby, the eruption of pests is the change of the pest status from secondary pest to key pest, especially due to the reduction in the population of natural enemies that keep pests below the level of economic loss (Fernandes et al., 2008). After application of insecticides, predators and parasitoids may acquire insecticides via host, direct contact or by ingesting floral nectar and pollen. Knowledge regarding the adverse effect of particular insecticide on important natural enemies is very limited and it causes difficulties in the selection of insecticides compatible with integrated pest management. Therefore, it necessitated to screen out the insecticides which are safer towards non-target organisms and have short persistency, as well as are compatible with IPM programme. Thus, a study was undertaken to evaluate some new and conventional insecticides with three different doses on Trichogramma chilonis Ishii and Bracon brevicornis Wesmael under laboratory condition.

\section{Materials and Methods}

Study site : Experiments were carried out on two indigenous parasitoids, T. chilonis (Trichogrammatidae: Hymenoptera) and $B$. brevicornis (Braconidae: Hymenoptera) in the Entomology Laboratory, Bidhan Chandra Krishi Viswavidyalaya, Kalyani, West Bengal, India. The eggs of rice meal moth (Corcyra cephalonica Stainton) were used as host for laboratory rearing of the egg parasitoid, T. chilonis, whereas full grown larvae (fifth instar) of $C$. cephalonica were used for rearing of $B$. brevicornis.
Insecticides used : Commercial formulations of pyridalyl 10EC, indoxacarb 14.5SC, chlorfenapyr 10SC, triazophos 40EC and chlorpyriphos $20 \mathrm{EC}$ were used against target natural enemies with three doses (half of the recommended, recommended and double the recommended dose for field use). Pyridalyl 10 EC (37.5, 75 and $150 \mathrm{~g}$ a.i. per ha), indoxacarb 14.5SC (37.5, 75 and $150 \mathrm{~g}$ a.i. per ha), chlorfenapyr $10 \mathrm{SC}$ (50,100 and $200 \mathrm{~g}$ a.i. per ha), triazophos $40 \mathrm{EC}(125,250$ and $500 \mathrm{~g}$ a.i. per ha) and chlorpyriphos $20 \mathrm{EC}(125,250$ and $500 \mathrm{~g}$ a.i. per ha) were tested for relative toxicity, whereas persistent toxicity study was conducted with only the recommended dose of insecticides.

\section{Mass culture of host and natural enemies}

Corcyra cephalonica: Method employed for mass culture of $C$. cephalonica Stainton was carried out following the method of Samanta et al. (2009), however, with slight modification. C. cephalonica was reared in glass jars measuring $20.5 \mathrm{~cm}$ length $\mathrm{x}$ $15 \mathrm{~cm}$ diameter using sterilized maize flour $\left(500 \mathrm{~g} \mathrm{jar}^{-1}\right)$ as culture medium. Approximately, 1000 Corcyra eggs were placed in each rearing jar. The mouth of each jar was covered with muslin cloth and kept undisturbed at $30 \pm 1^{\circ} \mathrm{C}$ without regulating of relative humidity for emergence of Corcyra adult. Immediately after the adult emergence, these were collected and released for egg laying in a double mouthed black colour glass cage $(15 \mathrm{~cm}$ length $12 \mathrm{~cm}$ diameter). One mouth of the egg laying cage was covered with a muslin cloth with a window (hole) on the cage to release Corcyra moth and the other mouth was covered with a wire net ( 30 mesh) to allow collection of Corcyra eggs on the petridish kept beneath. The egg laying cages were kept at $30 \pm 1^{\circ} \mathrm{C}$ and $75 \pm 5 \%$ relative humidity and the eggs were collected at different days intervals. Collected eggs were used for mass rearing of $T$. chilonis, while fully mature larvae (fifth instars) were used for mass rearing of $B$. brevicornis.

Trichogramma chilonis : Method employed by Samanta et al. (2009) for mass culture of $T$. chilonis was used with slight modification. Eggs of Corcyra of less than 12-hr-old were stored in deep freeze (below $0^{\circ} \mathrm{C}$ ) for $24 \mathrm{hrs}$ to kill the developing embryo. These were then sprinkled on a card $(15.5 \mathrm{~cm} \times 8 \mathrm{~cm})$ smeared with a uniform thin layer of $2 \%$ aqueous solution of pure gum Arabic, with the help of a camel hair brush to obtain a uniform layer of the eggs. Approximately, 20,000 (1 cc) eggs were glued on each card. One such egg card was offered to the parasite in each rearing unit (already established in laboratory). The parasitoids along with the egg card were kept in a temperature humidity control chamber at $26 \pm 2{ }^{\circ} \mathrm{C}$ and $70 \pm 5 \%$ relative humidity. The adult parasites were fed on a 1:1 solution of honey and distilled water drawn on the inner wall of the rearing unit with one fine brush so as to obtain fine streaks. Super parasitism was avoided by providing the optimum number of host eggs to the parasitoids. The egg card was removed from the rearing unit after $24 \mathrm{hr}$ and a fresh card was offered again for parasitisation and the process was continued till $50 \%$ of the parasites were dead, which 
were mostly males. After the parasitized eggs blackened, each egg card was divided into small pieces and each piece was kept in separate rearing units for the emergence of adult parasite.

Bracon brevicornis: For the rearing of parasitoid, the method was adopted followed by Samanta et al. (2009) with minor modification. Ten pairs of newly emerged adults of $B$. brevicornis were placed in a glass jar measuring $15 \mathrm{~cm}$ length $12.5 \mathrm{~cm}$ diameter and the mouth of the jar was covered with muslin. Aqueous solution of $10 \%$ sugar, soaked in cotton, was offered to the adult parasites as food. Thirty full grown larvae of $C$. cephalonica collected from the laboratory culture were placed on the cloth cover. After $24 \mathrm{hrs}$, the parasitized larvae were removed and placed in a petridish (12.5 cm in diameter) which was lined with a filter paper. The petridish was kept at $26 \pm 2{ }^{\circ} \mathrm{C}$ and $70 \pm 5 \%$ relative humidity. A new set of larvae was offered to the parasites and the process was continued till $50 \%$ of the parasites were dead, which were mostly males. After pupation of the parasite larvae, the unfed body portion of Corcyra larvae was removed with the help of a fine forceps and the pupae were kept in a glass jar measuring $20.5 \mathrm{~cm}$ length $10 \mathrm{~cm}$ diameter for the emergence of adult parasites.

\section{Treatment on different stages of natural enemies}

Treatment on pupae of $T$. chilonis: The parasitized egg cards were dipped in desired concentrations of each insecticide when the parasitoids were at pupal stage (4 days after parasitisation). The egg cards were then removed and dried under fan, and kept separately in glass vials to allow the emergence of the adult parasitoid from the insecticide treated host eggs. In control treatment, eggs were dipped in water. After emergence of adult parasitoids, mortality of the pupae was counted on the basis of parasitized eggs which failed to show adult emergence. Each treatment was replicated three times and observations were taken on 30 parasitized eggs in each replication (Samanta et al., 2009; Sattar et al., 2011).

Treatment on adults of $\boldsymbol{B}$. brevicornis: Castor leaf strips measuring $14 \mathrm{~cm} \times 5.5 \mathrm{~cm}$ and leaf circles of $4.2 \mathrm{~cm}$ diameter were dipped in various insecticidal solutions and dried under fan. In control treatment, the leaf strips were dipped in water. These rectangular leaf strips were then lined with the inner wall surface and leaf circles were placed on inner bottom of plastic container measuring $6.0 \mathrm{~cm}$ length $4.5 \mathrm{~cm}$ diameter. Ten numbers of newly emerged adult females of $B$. brevicornis were released with the help of small test tube into the container. The mouth of the plastic container was covered with cloth secured with rubber band and kept at $26 \pm 2^{\circ} \mathrm{C}$ and $70 \pm 5 \%$ relative humidity with bottom side upward to ensure constant contact of the parasitoid with the insecticide treated leaf strips. Mortality was recorded after 1, 24 and $48 \mathrm{hrs}$ of release and the moribund adults were considered as dead. Each treatment was replicated thrice (Ahmed and Ahmad, 2006; Samanta et al., 2009).
Treatment on larvae of $B$. brevicornis: Thirty larvae (one-dayold) of $B$. brevicornis were collected from host larvae and placed on petridish ( $9 \mathrm{~cm}$ diameter) for each treatment. Then these larvae were sprayed with desired concentration of different insecticides solution with three replications and dried under fan. Two types of control treatments viz. with water spray and without water spray on larvae were used. Treated larvae were kept at $26 \pm$ $2^{\circ} \mathrm{C}$ and $70 \pm 5 \%$ relative humidity. Observations were taken only after adult emergence.

Treatment on pupae of $B$. brevicornis: About fifty larvae (oneday-old) of $B$. brevicornis from host larvae were collected and placed on petridish ( $9 \mathrm{~cm}$ diameter) to allow pupa formation. After pupa formation, only thirty pupae were kept on petridish for each treatment and others were discarded. These pupae were then sprayed with desired concentration of different insecticides solution with three replications and dried under fan. In control treatment, sprays were done with water. Treated pupae were kept at $26 \pm 2^{\circ} \mathrm{C}$ and $70 \pm 5 \%$ relative humidity. Observations were taken only after adult emergence.

Persistent toxicity of insecticides on natural enemies : Each insecticide formulation was applied twice with recommended doses separately on cabbage in field at an interval of 15 days to work out the persistent toxicity of each insecticide on natural enemies. Leaves were collected from previously tagged plants from treated and untreated plots on 0 ( $2 \mathrm{hr}), 1,3,5,7$ and 10 days after second spray and parasites were exposed to the treated leaves of cabbage. Each treatment was replicated thrice along with control.

Persistent toxicity on adult of $T$. chilonis: Cabbage leaves collected from treated fields were cut into pieces of approximately $5 \mathrm{~cm} \times 1.5 \mathrm{~cm}$ with the help of the scissor. These were kept in glass tubes measuring $7.5 \mathrm{~cm}$ length $1.9 \mathrm{~cm}$ diameter and ten pairs of newly emerged females were released in each tube, the mouth of which was covered with nylon net. A few Corcyra eggs were glued on the leaves to keep the parasites in contact with leaf surface. Mortality of the adults was recorded after $6 \mathrm{hrs}$ at $26 \pm 2{ }^{\circ} \mathrm{C}$ and $70 \pm 5 \%$ relative humidity.

Persistent toxicity on adult of $\boldsymbol{B}$. brevicornis: Cabbage leaves collected from treated fields were cut into pieces of approximately $14 \mathrm{~cm} \times 5.5 \mathrm{~cm}$ leaf strip and leaf circle of $4.2 \mathrm{~cm}$ diameter, and then same methods were followed as applied in treatment on adults of $B$. brevicornis for relative toxicity. Mortality of adults was counted after $6 \mathrm{hrs}$ and moribund adults were treated as dead.

Statistical analysis: The data of mortality of different natural enemies were transformed into angular values and then analyzed following CRD. The percentage mortality obtained in different experiments for persistence toxicity study was corrected by Abbott's formula (1925): 


$$
P=\frac{P^{1}-C}{100-C} \times 100
$$

Where, $p$ is the percent corrected mortality, $p^{1}$ is the percent observed mortality and $\mathrm{c}$ is the percent mortality in control.

The relative persistent toxicity and residual toxicity was determined by a criterion developed by Pradhan and Venkataraman (1962). According to this criterion, the product (PT) of the average residual toxicity $(T)$ and the period $(P)$ for which the toxicity persisted was used as an index of persistent toxicity.

\section{Results and Discussion}

Effect on adult emergence from treated pupae of T. chilonis : There were significant differences observed among the insecticides, as well as treatments also on the emergence of adult from treated pupae of $T$. chilonis (Table 1). Among the insecticidal treatments, maximum emergence of adult was found from pyridalyl @ 37.5 and 75 g a.i. per ha and indoxacarb @ 37.5, 75 and $150 \mathrm{~g}$ a.i. per hawith $77.38,74.19,74.94,72.94$ and $71.51 \%$ adult emergence, respectively which were at par with untreated control (84.02 \% emergence). Though few emergences were noticed from chlorfenapyr and triazophos treated pupae (1.32 to $13.63 \%)$, but there was no emergence from chlorpyriphos treated pupae.
Persistent toxicity towards adults of $T$. chilonis on cabbage leaves : The mortality data of $T$. chilonis at different days intervals along with average residual toxicity and index of persistent toxicity (PT value) for different insecticides are depicted in Table 3. Pyridalyl was found to be less persistent insecticide, which killed the female adults of $T$. chilonis after only one day of spraying followed by indoxacarb, chlorfenapyr, triazophos and chlorpyriphos with 3, 5,7 and 7 days, respectively, after 6 hrs of exposure. The average residual toxicity $(\mathrm{T})$ was highest in chlorpyriphos 20 EC (33.67\%), while it was lowest in pyridalyl $(6.67 \%)$. Considering PT value of pyridalyl as unity, it was found that indoxacarb, chlorfenapyr, triazophos and chlorpyriphos persisted $5.70,11.06,30.78$ and 35.33 times more than pyridalyl at recommended dose.

In the present study, pyridalyl was safest insecticide to $T$. chilonis in terms of adult emergence $(74.19$ to $77.38 \%)$ from treated pupae and adult mortality on 0 day (16.67\%) and one day (3.33\%) due to persistent toxicity. To the best of our knowledge, there is very limited information on toxicity effect of pyridalyl on $T$. chilonis and $B$. brevicornis. It is reported that pyridalyl showed low toxicity to various beneficial arthropods (Saito et al., 2002; Sakamoto et al., 2004). Findings are in agreement with the study of Nair et al. (2008) who reported that pyridalyl was relatively safe to $B$. brevicornis, Chrysoperla carnea and T. chilonis on the basis of $\mathrm{LC}_{50}$ values. Indoxacarb was also less toxic insecticide to $T$. chilonis with 71.51 to $74.94 \%$ adult emergence from treated

Table 1: Effect of insecticides on adult emergence of $B$. brevicornis and T. chilonis

\begin{tabular}{|c|c|c|c|c|}
\hline \multirow[t]{2}{*}{ Treatments } & \multirow[t]{2}{*}{ Dose (g a.i. per ha) } & \multicolumn{3}{|c|}{ Percent adult emergence from treated stages of natural enemies } \\
\hline & & Pupae of T. chilonis & Larvae of Bracon & Pupae of Bracon \\
\hline \multirow[t]{3}{*}{ Pyridalyl $10 \mathrm{EC}$} & 37.5 & $77.38(61.60)$ & $37.78(37.93)$ & $90.63(72.18)$ \\
\hline & 75 & $74.19(59.46)$ & $17.78(24.94)$ & $88.87(70.51)$ \\
\hline & 150 & $70.11(56.86)$ & $13.33(21.42)$ & $89.13(70.75)$ \\
\hline \multirow[t]{3}{*}{ Indoxacarb 14.5SC } & 37.5 & $74.94(59.96)$ & $17.78(24.94)$ & $85.19(67.36)$ \\
\hline & 75 & $72.94(58.66)$ & $8.89(17.35)$ & $73.48(59.01)$ \\
\hline & 150 & $71.51(57.74)$ & $6.67(14.96)$ & 71.11(57.49) \\
\hline \multirow[t]{3}{*}{ Chlorfenapyr 10 SC } & 50 & $13.63(21.66)$ & 8.89(17.35) & $69.70(56.60)$ \\
\hline & 100 & $6.55(14.83)$ & $2.22(8.57)$ & $64.90(53.67)$ \\
\hline & 200 & $4.22(11.85)$ & $0.00(0.00)$ & $53.03(46.74)$ \\
\hline \multirow[t]{3}{*}{ Triazophos 40EC } & 100 & $10.44(18.85)$ & $0.00(0.00)$ & $52.53(46.45)$ \\
\hline & 200 & $4.78(12.63)$ & $0.00(0.00)$ & $47.22(43.41)$ \\
\hline & 400 & $1.32(6.60)$ & $0.00(0.00)$ & $38.89(38.58)$ \\
\hline \multirow[t]{3}{*}{ Chlorpyriphos 20EC } & 100 & $0.00(0.00)$ & $0.00(0.00)$ & $6.06(14.25)$ \\
\hline & 200 & $0.00(0.00)$ & $0.00(0.00)$ & $2.78(9.59)$ \\
\hline & 400 & $0.00(0.00)$ & $0.00(0.00)$ & $0.00(0.00)$ \\
\hline Control & Water & $84.02(66.44)$ & $48.89(44.36)$ & $93.17(74.86)$ \\
\hline Control & No water & - & $84.44(66.77)$ & - \\
\hline $\operatorname{SEm}( \pm)$ & & $(3.12)$ & $(2.66)$ & $(4.62)$ \\
\hline CD at $5 \%$ & & $(9.00)$ & (7.65) & (13.34) \\
\hline
\end{tabular}

Data in parentheses are the angular transformed values 
pupae and adult mortality $30 \%$ on 0 day and $26.67 \%$ on $1^{\text {st }}$ day in persistent toxicity study. Results are in conformity with the findings of Hewa-Kapuge et al. (2003) who reported that indoxacarb had a small impact $(<8 \%)$ on emergence of $T$. brassicae. Bhargavi (2016) reported that indoxacarb could be used before $T$. japonicum release in the field with some safe period. The recommended field dosages of indoxacarb and pyridalyl were found harmless to adults of T. chilonis (IOBC-class1, $<30 \%$ mortality) (Anoop et al., 2016). Present findings regarding safety of indoxacarb against $T$. chilonis is in agreement with earlier researchers (Ughade et al., 2002; Sattar et al., 2011). Chlorfenapyr showed more toxicity to $T$. chilonis in term of adult emergence (4.22 to $13.63 \%$ ), as well as persistent toxicity (50 and $36.67 \%$ adult mortality on 0 and 1 day, respectively). HewaKapuge et al. (2003) reported that chlorfenapyr caused 100\% mortality when directly applied to adults of $T$. brassicae and $95 \%$ mortality when adults were exposed to residues of these chemicals within $24 \mathrm{hrs}$ of application. Results are in concurrence with Nasreen et al. (2004) who reported that chlorfenapyr was found toxic for $T$. chilonis. High toxicity of chlorfenapyr on Trichogramma spp was also reported earlier (Carvalho et al., 2006; Wang et al., 2010). Chlorpyriphos (no adult emergence and $100 \%$ adult mortality on 1 day in persistent toxicity) and triazophos (1.32 to $10.44 \%$ adult emergence and $100 \%$ adult mortality on $1^{\text {st }}$ day in persistent toxicity) were highly toxic insecticides to T. chilonis in the present study. Zhao et al. (2012) reported that among the seven classes of chemicals tested, organophosphates (chlorpyriphos, fenitrothion, phoxim, profenofos, and triazophos) and carbamates (carbaryl, carbosulfan, isoprocarb, metolcarb, and promecarb) exhibited the highest intrinsic toxicity to T. japponicum. Chen et al. (2013) also reported that spinosad, chlorfenapyr, chlorpyriphos, triazophos, and imidacloprid were not safe for any development stage of $T$. nubilale. Triazophos and chlorpyriphos were harmful to adults of T. pretiosum (Sun et al., 2008; Stefanello-Junior et al., 2008).

Effect on adult emergence from treated larvae of $B$. brevicornis : Impact of insecticidal treatments on adult emergence from treated larvae of $B$. brevicornis is depicted in Table 1. From the control treatments with water $(48.89 \%$ emergence) and without water (84.44\% emergence), it was clear that water had a great impact on larvae in the formation of pupae as well as emergence of adult. Pyridalyl (37.5 to $150 \mathrm{~g}$ a.i. per ha) showed relatively higher emergence (13.33 to $37.78 \%$ ) than indoxacarb @ 37.5 to $150 \mathrm{~g}$ a.i. ha ${ }^{-1}$ with 6.67 to 17.78 per cent adult emergence. Triazophos (100 to $400 \mathrm{~g}$ a.i. per ha) and chlorpyriphos (100 to $400 \mathrm{~g}$ a.i. per ha) were most toxic insecticides with no adult emergence, followed by chlorfenapyr @ 50 to $200 \mathrm{~g}$ a.i. per ha ( 0 to $8.89 \%$ adult emergence).

Effect on adult emergence from treated pupae of $B$. brevicornis : Effect of insecticides on adult emergence from the treated pupae of $B$. brevicornis is illustrated in Table 1. There were no significant differences observed among the control $(93.17 \%$ emergence) and treatments with pyridalyl @ 37.5, 75 and $150 \mathrm{~g}$ a.i. per ha and indoxacarb @ $37.5 \mathrm{~g}$ a.i. per ha with $90.63,88.87$, 89.13 and $85.19 \%$ adult emergence, respectively. Indoxacarb @

Table 2 : Effect of insecticides on adult mortality of $B$. brevicornis

\begin{tabular}{|c|c|c|c|c|c|}
\hline \multirow[t]{2}{*}{ Treatments } & \multirow[t]{2}{*}{ Dose (ga.i. per ha) } & \multicolumn{4}{|c|}{ Percent mortality of adults of Bracon by leaf dipping method } \\
\hline & & $1 \mathrm{hr}$ & $24 \mathrm{hr}$ & $48 \mathrm{hr}$ & Mean \\
\hline \multirow[t]{3}{*}{ Pyridalyl $10 \mathrm{EC}$} & 37.5 & $0.00(0.00)$ & $0.00(0.00)$ & $10.00(18.43)$ & $3.33(10.52)$ \\
\hline & 75 & $0.00(0.00)$ & $3.33(10.52)$ & 13.33(21.42) & $5.56(13.63)$ \\
\hline & 150 & $0.00(0.00)$ & $5.56(13.63)$ & $23.33(28.88)$ & $9.63(18.08)$ \\
\hline \multirow{3}{*}{ Indoxacarb 14.5SC } & 37.5 & $0.00(0.00)$ & $5.56(13.63)$ & $47.78(43.73)$ & $17.78(24.94)$ \\
\hline & 75 & $0.00(0.00)$ & $16.67(24.09)$ & $71.11(57.49)$ & $29.26(32.75)$ \\
\hline & 150 & $0.00(0.00)$ & $45.56(42.45)$ & $81.11(64.24)$ & $42.22(40.53)$ \\
\hline \multirow[t]{3}{*}{ Chlorfenapyr 10 SC } & 50 & $0.00(0.00)$ & $98.89(83.95)$ & $100.00(90.00)$ & $66.30(54.51)$ \\
\hline & 100 & $4.44(12.17)$ & $100.00(90.00)$ & $100.00(90.00)$ & $68.15(55.64)$ \\
\hline & 200 & $20.00(26.57)$ & $98.89(83.95)$ & $100.00(90.00)$ & $72.96(58.67)$ \\
\hline \multirow{3}{*}{ Triazophos 40EC } & 100 & $86.67(68.58)$ & $100.00(90.00)$ & $100.00(90.00)$ & $95.56(77.83)$ \\
\hline & 200 & $100.00(90.00)$ & $100.00(90.00)$ & $100.00(90.00)$ & $100.00(90.00)$ \\
\hline & 400 & $100.00(90.00)$ & $100.00(90.00)$ & $100.00(90.00)$ & $100.00(90.00)$ \\
\hline \multirow[t]{3}{*}{ Chlorpyriphos 20EC } & 100 & $100.00(90.00)$ & $100.00(90.00)$ & $100.00(90.00)$ & $100.00(90.00)$ \\
\hline & 200 & $100.00(90.00)$ & $100.00(90.00)$ & $100.00(90.00)$ & $100.00(90.00)$ \\
\hline & 400 & $100.00(90.00)$ & $100.00(90.00)$ & $100.00(90.00)$ & $100.00(90.00)$ \\
\hline Control & Water & $0.00(0.00)$ & $0.00(0.00)$ & $6.67(14.96)$ & $2.22(8.57)$ \\
\hline $\operatorname{SEm}( \pm)$ & & $(2.44)$ & $(2.91)$ & $(3.92)$ & $(2.47)$ \\
\hline CD at $5 \%$ & & $(7.04)$ & (8.42) & (11.33) & $(7.13)$ \\
\hline
\end{tabular}

Data in parentheses are the angular transformed values 
Table 3 : Persistent toxicity of insecticides on adults of T. chilonis

\begin{tabular}{|c|c|c|c|c|c|c|c|c|c|c|c|}
\hline \multirow[t]{2}{*}{ Treatments } & \multirow{2}{*}{$\begin{array}{l}\text { Dose (g a.i. } \\
\text { per ha) }\end{array}$} & \multicolumn{6}{|c|}{ Mortality of adults at days interval with $6 \mathrm{hr}$ exposure } & \multirow{2}{*}{$\begin{array}{l}\text { Period } \\
\text { (P) }\end{array}$} & \multirow{2}{*}{$\begin{array}{l}\text { Average } \\
\text { toxicity }(\mathrm{T})\end{array}$} & \multirow[t]{2}{*}{ PT } & \multirow[t]{2}{*}{ ORS } \\
\hline & & $\mathrm{Od}$ & $1 \mathrm{~d}$ & $3 d$ & $5 d$ & $7 d$ & $10 \mathrm{~d}$ & & & & \\
\hline Pyridalyl 10EC & 75 & 16.67 & 3.33 & 0 & & & & 1 & 6.67 & 6.67 & 1.00 \\
\hline Indoxacarb14.5SC & 75 & 30 & 26.67 & 6.67 & 0 & & & 3 & 12.67 & 38.00 & 5.70 \\
\hline Chlorfenapyr 10SC & 100 & 50 & 36.67 & 13.33 & 3.33 & 0 & & 5 & 14.76 & 73.81 & 11.06 \\
\hline Triazophos 40EC & 250 & 100 & 100 & 60 & 26.67 & 6.67 & 0 & 7 & 29.33 & 205.34 & 30.78 \\
\hline Chlorpyriphos 20EC & 250 & 100 & 100 & 76.67 & 46.67 & 13.33 & 0 & 7 & 33.67 & 235.67 & 35.33 \\
\hline
\end{tabular}

$\mathrm{P}=$ Period in days; $\mathrm{T}=$ Average residual toxicity; $\mathrm{PT}=$ Index of persistent toxicity; ORS= order of relative safety

Table 4 : Persistent toxicity of insecticides on adults of $B$. brevicornis

\begin{tabular}{|c|c|c|c|c|c|c|c|c|c|c|}
\hline \multirow[t]{2}{*}{ Treatments } & \multirow{2}{*}{$\begin{array}{l}\text { Dose (g a.i. } \\
\text { per ha) }\end{array}$} & \multicolumn{5}{|c|}{ Mortality of adults at days interval with $6 \mathrm{hr}$ exposure } & \multirow{2}{*}{$\begin{array}{l}\text { Period } \\
\text { (P) }\end{array}$} & \multirow{2}{*}{$\begin{array}{l}\text { Average } \\
\text { toxicity (T) }\end{array}$} & \multirow[t]{2}{*}{ PT } & \multirow[t]{2}{*}{ ORS } \\
\hline & & od & 1d & $3 d$ & $5 d$ & $10 \mathrm{~d}$ & & & & \\
\hline Pyridalyl 10EC & 75 & 13.33 & 3.33 & 0 & & & 1 & 5.55 & 5.55 & 1.00 \\
\hline Indoxacarb14.5SC & 75 & 16.67 & 6.67 & 0 & & & 1 & 7.78 & 7.78 & 1.40 \\
\hline Chlorfenapyr 10SC & 100 & 26.67 & 16.66 & 3.33 & 0 & & 3 & 9.33 & 28.00 & 5.04 \\
\hline Triazophos 40EC & 250 & 50 & 10 & 6.67 & 0 & & 3 & 13.33 & 40.00 & 7.21 \\
\hline Chlorpyriphos 20EC & 250 & 100 & 100 & 76.67 & 13.33 & 0 & 5 & 41.43 & 207.14 & 37.32 \\
\hline
\end{tabular}

$\mathrm{P}=$ Period in days; $\mathrm{T}=$ Average residual toxicity; $\mathrm{PT}=$ Index of persistent toxicity; $\mathrm{ORS}=$ order of relative safety

$150 \mathrm{~g}$ a.i. per ha $(71.11 \%$ emergence $)$ was at par with chlorfenapyr @ 50 and $100 \mathrm{~g}$ a.i. per ha with 69.70 and $64.90 \%$ adult emergence, respectively. Triazophos at recommended (200 $\mathrm{g}$ a.i. per ha) and double the recommended dose (400 $\mathrm{g}$ a.i. per ha) recorded 47.22 and 38.89 per cent adult emergence, respectively. Chlorpyriphos at all doses was highly toxic towards pupae of $B$. brevicornis. Thus chlorpyriphos and triazophos had high impact on pupae of $B$. brevicornis.

Effect on adults of $B$. brevicornis : Highly significant variation in adult mortality of $B$. brevicornis was observed among the insecticides with different exposure time. Table 2 reveals that pyridalyl and indoxacarb at all doses and chlorfenapyr at lower doses were very safe to the adults of $B$. brevicornis with $1 \mathrm{hr}$ exposure. Pyridalyl recorded low mortality (10.00 to $23.33 \%$ ) even when exposure time was increased up to $48 \mathrm{hr}$, but in the case of indoxacarb, mortality increased (47.78 to $81.11 \%$ ) gradually with increase of exposure time. Chlorfenapyr, triazophos and chlorpyriphos showed different trend of mortality as compared to other insecticides where mortality suddenly reached $100 \%$ with increase in exposure time from $1 \mathrm{hr}$ to $24 \mathrm{hr}$ (Table 2). In control, only $6.67 \%$ mortality was recorded after 48 hrs of exposure. Low mean mortality (3.33 to $9.63 \%$ ) was also recorded in pyridalyl @ 37.5 to $150 \mathrm{~g}$ a.i. per ha treatment followed by indoxacarb @ 37.5 to $150 \mathrm{~g}$ a.i. per ha treatment (17.78 to $42.22 \%)$. Other insecticides were extremely toxic towards adults of $B$. brevicornis, whereas in control mean mortality was only $2.22 \%$.
Persistent toxicity towards adults of $B$. brevicornis on cabbage : Persistence toxicity of insecticides against adults of $B$. brevicornis is presented in Table 4. Persisted residue in cabbage leaves brought the mortality of $B$. brevicornis up to 5 days of spraying in chlorpyriphos treatment. Next persisted insecticides were chlorfenapyr and triazophos which showed mortality up to 3 days of spraying, whereas pyridalyl and indoxacarb were less persistent insecticides which brought mortality only up to 1 day of spraying. Average toxicity was less in pyridalyl (5.55\%), followed by indoxacarb (7.78\%), chlorfenapyr (9.33\%), triazophos (13.33\%) and chlorpyriphos (41.43\%). Based on the persistent toxicity index (PT), it was observed that indoxacarb, chlorfenapyr, triazophos and chlorpyriphos were 1.40, 5.04, 7.21 and 37.32 times more persistent than pyridalyl.

Literature on toxicity of these insecticides against $B$. brevicornis is meagre, therefore; results may be compared with other natural enemies. Toxicity of pyridalyl on natural enemies has been discussed earlier. Pietrantonio and Benedict (1999) revealed that residues of chlorfenapyr were toxic to Cotesia plutellae and C. marginiventris. The results of the present study is in line with Haseeb and Amano (2002) who reported that chlorfenapyr was selective against the cocoon stage of $C$. plutellae, while moderate to extremely toxic (80 to $100 \%$ lethal) to wasp stage of C. plutellae. Patil et al. (1990) reported that monocrotophos and chlorpyriphos were toxic to all stages of the ectoparasitoids Goniozus nephantidis and B. brevicornis. The higher rate of chlorpyriphos gave $100 \%$ mortality of $B$. hebetor 
after $24 \mathrm{hrs}$ of application, even at lower and recommended doses, 100 per cent mortality was recorded after $36 \mathrm{hrs}$ of application (Khan et al., 2009). Liu et al. (2016) reported that indoxacarb and chlorfenapyr showed no toxicity on Harmonia axyridis, Chrysoperla sinica, Snelleniua manilae and Telenomus remus pupae with the recommended field concentrations, while indoxacarb, chlorfenapyr and chlorpyrifos showed dangerously toxic and long risk duration on S. manilae and T. remus adults.

From the present study, it is concluded that pyridalyl and indoxacarb were less toxic and short persistent in nature and thereby, both the insecticides would be compatible with biological control and these natural enemies could be released in to the field with maximum of 3 days safe waiting period after application of these insecticides. Furthermore, the index of persistent toxicity of the present experiment will be useful tool for selecting the less persistent insecticides for successful integrated pest management.

\section{Acknowledgment}

First author is highly thankful to the Director, ICAR RC for NEH Region, Umiam, Meghalaya, India for his encouragement and support to carry out this research.

\section{References}

Abbott, W.S.: A method of computing the effectiveness of insecticides. J. Econ. Ent., 18, 265-267 (1925).

Ahmed, S. and M. Ahmad: Toxicity of some insecticides on Bracon hebetor under laboratory conditions. Phytoparasitica, 34, 40- 404 (2006).

Anoop, K., N.N. Singh and V.K. Mishra: Safety of insecticides to egg parasitoid Trichogramma chilonis Ishii. Indian J. Ent., 78, 82-88 (2016).

Bhargavi, M.: Sensitivity of Trichogramma japonicum (Ashmead) to different insecticides. Asian J. Sci. Tech., 7, 2585-2587 (2016).

Carvalho, G.A., A.P. Moura and V.H.P. Bueno: Side effects of pesticides on Trichogramma pretiosum (Hymenoptera: Trichogrammatidae). Bull. OILB/SROP, 29, 355-359 (2006).

Chen, X., M. Song, S. Qi and C. Wang: Safety evaluation of eleven insecticides to Trichogramma nubilale (Hymenoptera: Trichogrammatidae). J. Econ. Ent., 106, 136-141 (2013).

Darwish, E., M. El-Shazly and H. El-Sherif: The choice of probing sites by Bracon hebetor (Say) (Hymenoptera: Braconidae) foraging for Ephestia kuehniella Zeller (Lepidoptera:Pyralidae). J. Stored Prod. Res., 39, 265-276 (2003).

Fernandes, M.E.S., F.L. Fernandes, M.C. Picanço, R.B. Queiroz, R.S. Silva and A.A.G. Huertas: Physiological selectivity of insecticides to Apis mellifera (Hymenoptera: Apidae) and Protonectarina sylveirae (Hymenoptera: Vespidae) in citrus. Sociobiology, 51, 765-774 (2008).

Gul, M. and A. Gulel: Parasitoid Bracon hebetor (Say) (Hymenoptera: Braconidae)'un biyolojisi ve konak larva büyüklüğünün verim ve eşey oranı üzerine etkisi. Turkish J. Zool., 19, 231-235 (1995).

Haseeb, M. and H. Amano: Effects of contact, oral and persistent toxicity of selected pesticides on Cotesia plutellae (Hymenoptera:
Braconidae), a potential parasitoid of Plutella xylostella (Lepidoptera: Plutellidae). J. Appl. Ent., 126, 8-13 (2002).

Heimpel, G.E., M.F. Antolin, R.A. Franqu and M.R. Strand: Reproductive isolation and genetic variation between two strains of Bracon hebetor (Hymenoptera: Braconidae). Biol. Cont., 9, 149-156 (1997).

Hewa-Kapuge, S., S. McDougall and A.A. Hoffmann: Effects of methoxyfenozide, indoxacarb, and other insecticides on the beneficial egg parasitoid Trichogramma nr. brassicae (Hymenoptera: Trichogrammatidae) under laboratory and field conditions. J. Econ. Ent., 96, 1083-1090 (2003).

Khan, R.R., A. Muhammad, A. Sohail and S.T. Sahi: Mortality responses in Bracon hebetor (Say) (Braconidae: Hymenoptera) against some new chemistry and conventional insecticides under laboratory conditions. Pakist. J. Agric. Sci., 46, 30-33 (2009).

Li, L.Y.: Worldwide use of Trichogramma for biological control on different crops: A survey. In: Biological control with egg parasitoids (Eds.: E. Wanjnberg and S.A. Hassan). pp.37-53 (1994).

Liu, Y., X. Li, C. Zhou, F. Liu and W. Mu: Toxicity of nine insecticides on four natural enemies of Spodoptera exigua. Sci. Rept., 6, 39060 (2016) (DOI: 10.1038/srep39060)

Mani, M., A. Krishnamoorthy and C. Gopalakrishnan: Biological control of lepidopterous pests of horticultural crops in India. A Rev. Agric. Res., 26, 39-49 (2005)

Nair, N., K. Sekh, P.P. Dhar and A.K. Somchoudhury: Field efficacy of pyridalyl $10 \mathrm{EC}$ against Helicoverpa armigera Hub. and its effect on its natural enemies. J. Ent. Res., 32, 237-240 (2008).

Nasreen, A., G. Mustafa, M. Ashfaq and M.A. Saleem: Combined effect of Chrysoperla carnea Stephen (Neuroptera: Chrysopidae) and Trichogramma chilonis Ishii (Hymenoptera: Trichogrammatidae) on Helicoverpa armigera eggs in the presence of insecticides. Pakist. J. Zool., 36, 189-191 (2004).

Patil, R.K., S. Lingappa and H. Basappa: Effect of insecticides and a chitin inhibitor on development of three parasitoids of the coconut black headed caterpillar Opisina arenosella Walker (Lepidoptera: Xyloryctidae). J. Oilseeds Res., 7, 51-57 (1990).

Pietrantonio, P.V. and J.H. Benedict: Effect of new cotton insecticide chemistries, tebufenozide, spinosad and chlorfenapyr on Orius insidious and two Cotesia species. Southwe. Entomol., 24, 21-29 (1999).

Pradhan, S. and T.V. Venkataraman: Integration of chemical and biological control of Chilo zonellus (Swinhoe), the stalk borer of maize and jowar. Bull. Nat. Inst. Sci. India, 19, 119-125(1962).

Saito, S., S. Isayama, N. Sakamoto, K. Umeda and K. Kasamatsu: Pyridalyl: A novel insecticidal agent for controlling lepidopterous pests. The BCPC Conference: Pests and diseases, Proceedingsof-an-international-conference held at Brighton Hilton Metropole Hotel, Brighton, UK, pp. 33-38 (2002).

Sakamoto, N., S. Saito, T. Hirose, M. Suzuki, S. Matsuo, K. Izumi, T. Nagatomi, H. Ikegami, K. Umeda, K. Tsushima and N. Matsuo: The discovery of pyridalyl: A novel insecticidal agent for controlling lepidopterous pests. Pest Mgmt. Sci., 60, 25-34 (2004).

Samanta, A., S. Patra, K. Chakraborti, A. Ghosh, T. K. Hembram and A.K. Somchowdhury: Relative toxicity of some insecticides against two indigenous parasites associated with Lepidopteran pests. Envir. Ecol., 27, 1545-1549 (2009).

Sattar, S. F., A. R. Saljoqi, M. Arif, H. Sattar and J.I. Qazi: Toxicity of some new insecticides against Trichogramma chilonis (Hymenoptera: Trichogrammatidae) under laboratory and extended laboratory conditions. Pakist. J. Zool., 43, 1117-1125(2011). 
Sharma, S. and N. Aggarwal: Dispersal ability and parasitisation performance of Trichogramma spp (Hymenoptera: Trichogrammatidae) in organic Basmati rice. J. Environ. Biol., 36, 1345-1348 (2015)

Stefanello-Junior, G.J., A.D. Grutzmacher, D.D. Grutzmacher, G.O. Dalmazo, M.D.F. Paschoal and W.R. Harter: The effect of insecticides used in corn crops on the parasitism capacity of Trichogramma pretiosum Riley, 1879 (Hymenoptera: Trichogrammatidae). Arquivos do Instituto Biologico Sao Paulo, 75, 187-194 (2008)

Sun, C., J. Su, J. Shen and X. Zhang: Laboratory safety evaluation of insecticides to Trichogramma japonicum. Chin. J. Rice Sci., 22, 93-98 (2008).

Ughade, J., S.R. Katole, S.V. Sarode and A.Y. Deshmukh: Effect of third day insecticidal application on the emergence of Trichogramma chilonis Ishii from parasitized host eggs. PKV Res. J., 26, 44-46 (2002).
Wang, D., L. Lv, Y. He, S. Qin and F. Pan: Effect of conventional insecticides on Trichogrammatoidea bactrae. Chin. Bull. Ent., 47, 379-383 (2010).

Wang, Z.Y., K.L. He, F. Zhang, X. Lu and D. Babendreier: Mass rearing and release of Trichogramma for biological control of insect pests of corn in China. Biol. Cont., 68, 136-144 (2014).

Yasumatsu, K.: Distribution and bionomics of natural enemies of rice stem borer. Mushi, 39 (Suppl.), 33-44 (1967).

Zhang, F., Z.Y. Babendreier, K.S.I. Wang, L. Zheng, Y.C. Pyon, S.X. Bai, K. Song, J.O. Ri, M. Grossrieder and U. Kuhlmann: Mass releases of Trichogramma ostriniae increase maize production on DPR Korea. J. Appl. Ent., 134, 481-490 (2010).

Zhao, X., C. Wu, Y. Wang, T. Cang, L. Chen, R. Yu and Q. Wang: Assessment of toxicity risk of insecticides used in rice ecosystem on Trichogramma japonicum, an egg parasitoid of rice lepidopterans. J. Econ. Ent., 105, 92-101 (2012). 